\title{
PEDESTRIAN MORTALITY IN RUSSIA: A CONTINUOUS DECLINE OVER THE LAST 25 YEARS?
}

\author{
ANASTASIYA PYANKOVA, TIMUR FATTAKHOV
}

\begin{abstract}
Using different data sources (HCoD, IRTAD, UNECE statistical database, police data), our research shows that the significant excess of pedestrian mortality over motor vehicle occupant mortality in 1988-1999 in Russia, according to RusFMD, is an abnormal phenomenon that most likely never occurred. Police data is preferable for assessing mortality levels by road user types in Russia. According to Russian police data, pedestrian mortality never exceeded motor vehicle occupant mortality. The steady decline of pedestrian mortality began in 2003, not in 1993, as vital statistics show. In 2008, pedestrian mortality for the first time reached the minimum level of the Soviet period. After significant fluctuations, motor vehicle occupant mortality dropped to the level of the early 1970s only in 2015-2017. The use of vital statistics is possible if it is necessary to differentiate road traffic mortality by sex, age, and type of settlements. Categorisation by road user types should be done with caution, using the following data sources: HCoD data from 1988 and RusFMD data from 1970 to 1988 and after 1999. It is suggested that difficulties in analysing long-term mortality by road user types based on vital statistics may occur in post-Soviet countries, where the Soviet abridged classification of causes of death (SC) was used. The prevalence of deaths coded by unspecified Vcodes (V89) should also be considered.
\end{abstract}

Key words: pedestrians, car occupants, road users, road traffic mortality, vital statistics, police data.

\section{INTRODUCTION}

It is necessary to understand the differentiation of road traffic mortality by socio-demographic and other characteristics, including road user types, for developing effective road safety measures. There is a well-known differentiation of the share of pedestrian fatalities of total road traffic fatalities by the economic well-being of countries (World Health Organization 2018; Yasin, Grivna, Abu-Zidan 2020): the lower the GDP per capita, the higher the proportion of pedestrians among all fatalities in road traffic accidents and the higher the pedestrian mortality (Eid, AbuZidan 2015; Sengoelge, Laflamme, El-Khatib 2018).

Using the Russian fertility and mortality database (hereinafter RusFMD) for 1965-1998 and depersonalised data of Rosstat for 2000-2017 appears to show that significant progress was made in reducing pedestrian mortality after a sharp rise in the late 1980s and a corresponding peak in the early 1990s (Figure 1). Starting in 1993, pedestrian mortality decreased by 5 times, coming to 3.2 deaths per 100 thousand people in 2017. The mortality of drivers and passengers did not experience such sharp ups and downs until the end of the 1990s.

Anastasiya Pyankova (apyankova@hse.ru), National Research University Higher School of Economics, RUSSIA.

Timur Fattakhov (tfattahov@hse.ru), National Research University Higher School of Economics, Russia.

THE STUDY WAS CARRIED OUT WITH THE FINANCIAL SUPPORT OF THE RUSSIAN FOUNDATION FOR BASIC RESEARCH WITHIN THE FRAMEWORK OF THE SCIENTIFIC PROJECT NO. 19-013-00060.

THE ORIGINAL ARTICLE IN RUSSIAN WAS PUBLISHED IN DEMOGRAPHIC REVIEW IN 2019, 7(4), 62-81.

DOI: 10.17323/DEMREVIEW.V7I4.12044 


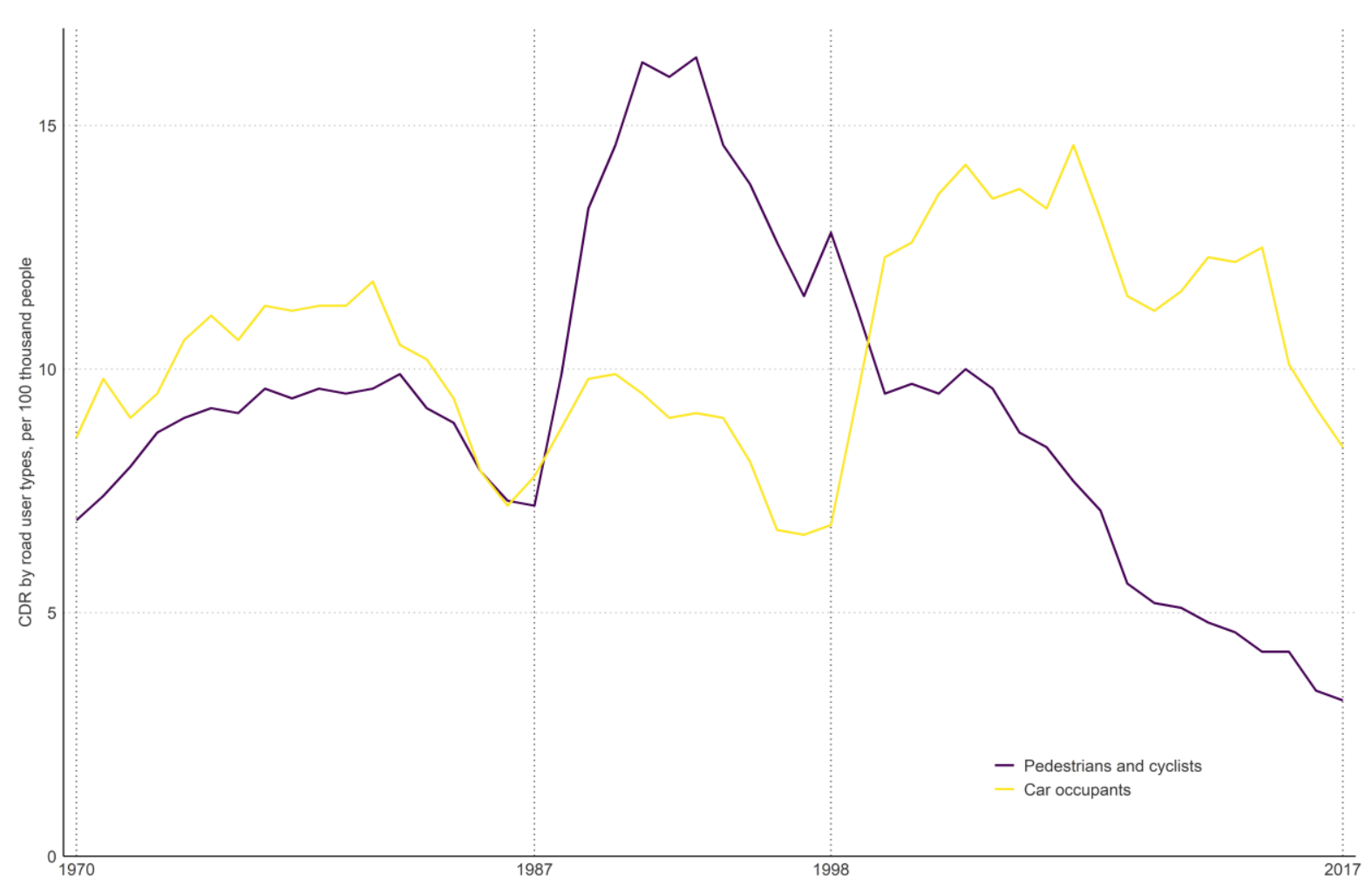

Figure 1. Mortality of main road users in Russia, 1970-2017

Note: $C D R$ is the crude death rate.

Source: RusFMD and Rosstat data.

The dynamics of pedestrian mortality by gender, urban and rural areas show the same trends (Figure 2). The male pedestrian mortality in urban areas decreased 6 times (from 26 to 4 deaths per 100 thousand people in 1993-2017), and in rural areas over the same period - 4 times. For female pedestrians, the corresponding rates decreased 4 and 3 times. The same tendencies are typical for all age groups.

Such a steady and long-term decline in pedestrian mortality, both in general and in more detailed categories of road users, raised a number of questions for us.

In principle, is it possible for pedestrian mortality to exceed the mortality of drivers and passengers for a significantly long time, as was the case in the late 1980s and 1990s in Russia according to RusFMD data (Figures 1 and 2)? This phenomenon contradicts the results of systematic reviews on this issue, which indicate that, while the proportion of pedestrian fatalities varied greatly across WHO regions, it exceeded $50 \%$ of all road traffic deaths only in the African region. At the same time, on average for countries with low, medium and high levels of well-being, the proportion of pedestrian deaths was 45, 30 and 20\%, respectively (Charters, Gabbe, Mitra 2017; Naci, Chisholm, Baker 2009). 

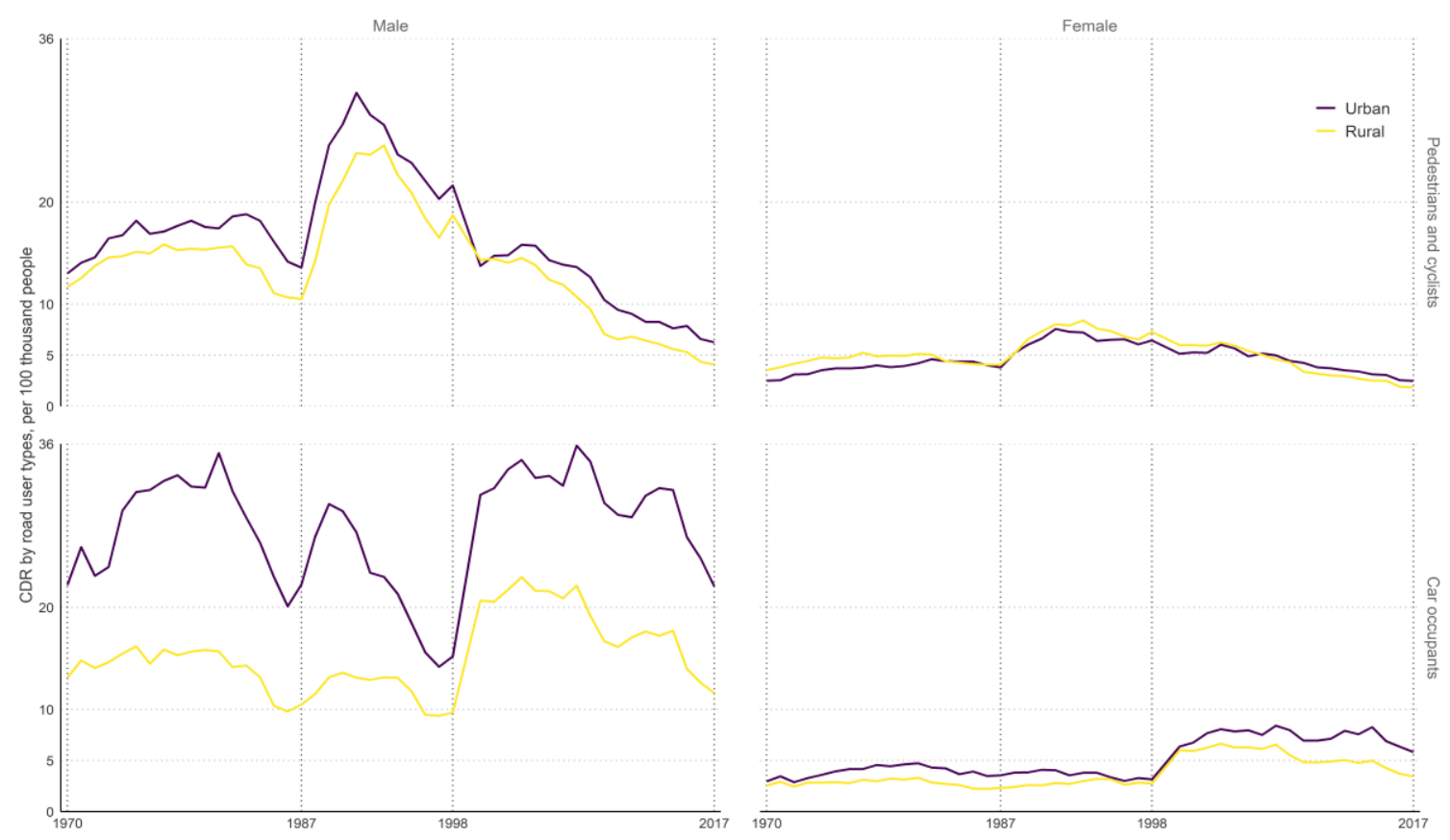

Figure 2. Differentiation of road traffic mortality in Russia, 1970-2017

Source: RusFMD and Rosstat data.

Why isn't there a second peak in pedestrian mortality in the late 1990s and early 2000s? A second peak in mortality was characteristic of drivers and passengers, as well as of most external causes of death (Vishnevsky 2017).

What explains such a slight increase in the mortality of drivers and passengers after the end of the anti-alcohol campaign and such a sharp increase in 1999? On the one hand, this does not correspond to mortality dynamics of external causes of death in Russia during this period. On the other hand, it contradicts the riskier behaviour recorded by the police of drivers than of pedestrians in the late 1980s. In the statistical collections of the Ministry of Internal Affairs, it is noted that in 1989 in the USSR "of all the drivers who caused road traffic accidents, 39.8\% did not have the right to drive the corresponding category of vehicle, $22.1 \%$ were drunk. One in five pedestrians responsible for road accidents was also drunk" (Crime and Offenses ... 1990).

How possible is the asynchrony of the dynamics of mortality among pedestrians and drivers and passengers observed in the late 1990s and up to the mid-2000s, when the mortality of drivers and passengers grew rapidly, while that of pedestrians continued to decline? The death rates of the main road user types are interconnected, since the behaviour of drivers largely determines the mortality of pedestrians. Therefore, if the mortality of drivers rises sharply, then this should partially affect pedestrian mortality .

These questions determined the goal of our study: to understand what caused the significant excess of pedestrian mortality over driver and passenger mortality in Russia according to the RusFMD in the late 1980s and early 1990s, and to verify this data source, comparing it with other, both accessible and not easily accessible, data sources on road traffic mortality in Russia and other countries. In this regard, the main aim of the study was to reconstruct the number of fatalities in road traffic accidents by road user types according to Soviet and then Russian police data for the same period. 


\section{DATA AND METHODS}

Within the framework of the reporting system of the Ministry of Internal Affairs, the following categories of road users are distinguished: 1) pedestrians and cyclists; 2) drivers and passengers. Information was obtained on the total number of fatalities in road traffic accidents, including by category of road users, according to the Russian Ministry of Internal Affairs and data from the traffic police in other countries ${ }^{1}$ :

- for the USSR, Russia, Latvia and Moldova for 1970-1989, from statistical reports regularly issued by the Scientific Research Center for Road Safety of the USSR Ministry of Internal Affairs (Scientific Research Center for Road Safety... n.d.);

- for Russia for 1990-1991, from the statistical collections "Crime and Offenses";

- for Russia for 1993-2004 and all other post-Soviet countries for 1993-2018, from the UNECE Statistical Database 2020;

- for Russia for 2005-2014, from the collective monograph (Vishnevsky 2017); since 2015, the relevant data of the Ministry of Internal Affairs are available online ${ }^{2}$;

- for a number of countries in Europe, the USA and South Korea for 1970-2010, from the International Road Traffic and Accident Database (IRTAD), data was obtained in 2012, when this data source was opened free of charge. Currently, free access to IRTAD data on the number of deaths by road user types is closed.

If in Russia, Latvia and Moldova for any year from 1970 to 1989 there were no data on fatalities by road user types, we assumed it to be similar to the structure of fatalities in the USSR for the same year, which was reconstructed for each year. In this case, the absolute number of fatalities by road user types was obtained based on the absolute number of fatalities in a given country in a given year and the pattern of mortality by road user types in the USSR in the same year. In addition, the lack of age structure of road traffic fatalities reported by the police did not allow us to use standardised death rates, so we analysed the crude death rates by road users.

We used the age-specific death rates for the period from 1970 to 1999 from the RusFMD database, which accumulates Russian mortality statistics. The sum of the deaths under item Nos. 160 and 161 of the Soviet abridged classification of causes of death of the 1988 revision (SC1988) was considered as deaths in motor vehicle traffic accidents. Deaths under item No. 160 were considered to be of drivers and passengers, and those under No. 161 - of pedestrians and cyclists. From 2000 to 2017 the definition of death in "Motor vehicle traffic accidents" was used, and the corresponding three-digit ICD-10 cause of death codes were aggregated: V02-V04, V09, V12V14, V20-V79, V82-V87, V89. Pedestrians and cyclists were coded by V02-V04, V09, V12-V14, and drivers and passengers - by V20-V79, V82-V87, V89.

\footnotetext{
${ }^{1}$ In different historical periods in Russia, the division of the Ministry of Internal Affairs responsible for road safety has had different official names. At the moment, the traffic police of the Ministry of Internal Affairs of the Russian Federation is responsible for the statistics of road accidents. This body, in terms of its functions, corresponds quite well to the generalized concept of "road police" which we use in relation to other countries, without going into the national characteristics of its ministerial hierarchy.

${ }^{2}$ URL: http://stat.gibdd.ru/
} 
To compare Russia with other post-Soviet countries, we used the crude death rates from The Human Cause-of-Death Database (HCoD). For Russia, the sum of the following items of the Russian abridged classification of the 2006 revision (RC-2006) was considered as pedestrian deaths: 1) 239. Pedestrian injured in transport accident; 2) 272. Pedestrian injured in collision with motor vehicle, nontraffic accident. For Estonia, Latvia, Lithuania and Moldova, the corresponding item for pedestrian fatalities was No.196, "Pedestrian injured in collision with motor vehicle" (codes V02-V04, V09), from the abbreviated list of causes of death for these countries, presented in the meta-data on the HCoD website.

The number of fatalities of drivers and passengers in Russia was defined as the sum of deaths under the following items: 1) 240. Car occupant injured in transport accident; 2) 241. Occupant of other transport vehicle in transport accident; 3) 273. Other persons injured in collision with motor vehicle, nontraffic accident. For Estonia, Latvia, Lithuania and Moldova, the corresponding item for driver and passenger fatalities was No. 195, "Transport accident with motor vehicle" (codes V12-V14, V19, V20-V79, V82, V87). Pedestrian fatalities in these countries are quite similar to the sum of two Russian items (Nos. 239 and 272) in terms of the composition of the ICD-10 codes (V02-V04, V09). The non-inclusion of Belarus and Ukraine is explained by a different composition of the item that could be referred to as pedestrians. In these countries, it is wider (V01-V09), and includes the relatively large, in terms of the numbers of deaths, code V05 (Pedestrian injured in collision with a train or other railway vehicle).

The composition of item No. 195, "Transport accident with motor vehicle" (codes V12V14, V19, V20-V79, V82, V87), is not fully comparable with the sum of Russian item Nos. 240241 and 273, which can be used to differentiate between the deaths of drivers and passengers. In Russia, these items include the codes V84-86, V88 and, partially, V80-81, V83, and V89. However, this did not significantly affect the mortality of Russian drivers or passengers according to HCoD data, since the number of deaths encoded with these codes is small. In 2014, it came to 614 people or $3.3 \%$ of the number of driver and passenger fatalities (of the total number of fatalities under item Nos. 240, 241, 273).

\section{RESULTS}

\section{Mortality of road users in Russia according to vital statistics and police data}

According to vital statistics and police data, crude death rates due to road traffic accidents did not differ significantly for a long time in Russia (see Figure 3 in (Pyankova, Fattakhov 2020)). The discrepancies in the number of deaths and, correspondingly, the crude death rates according to police data and vital statistics are in line with similar indicators seen in other countries (see Appendix 1 in (Pyankova et al. 2019).

In order to answer the questions posed regarding the dynamics of mortality among pedestrians and drivers and passengers according to vital statistics, we decided first to assess how they are applicable to similar indicators calculated according to police data.

Police data indicate the following (Figure 3). First, the mortality of pedestrians and cyclists has never exceeded the mortality of drivers and passengers, in contrast to similar indicators 
calculated based on RusFMD data . Second, the second peak of pedestrian and cyclist mortality in the late 1990s and early 2000s was as high as for drivers and passengers and most external causes of death. Third, the mortality increase of drivers and passengers after the end of the anti-alcohol campaign was sharp: the crude death rate (CDR) for 4 years from 1987 to 1991 almost doubled, reaching the highest value ever recorded in 1991. The second wave of mortality increase of drivers and passengers occurred between 2000 and 2007, and was smoother. Fourth, the changes in the mortality of pedestrians and cyclists and drivers and passengers throughout the observation period are consistent: an increase in the mortality of drivers and passengers corresponds to an increase in the mortality of pedestrians and cyclists, including in 1998-2002. A steady mortality decline of pedestrians and cyclists began in 2003, marking the beginning of a road traffic mortality decline in Russia as a whole. In 2003-2014, declining pedestrian mortality corresponded to a fluctuation in the mortality of drivers and passengers at the fairly high level of from 12 to 14 deaths per 100 thousand people. From 2014 onwards, there began a decline in the deaths rates of drivers and passengers causing a continuing downward trend among pedestrians and cyclists and an overall intensification of road traffic mortality in Russia.

As a result, the mortality dynamics of the main road user types according to police data differ from similar indicators based on RusFMD data. No peculiarities of the road traffic mortality arising in the analysis of Figure 1 and expressed in the research questions are revealed.

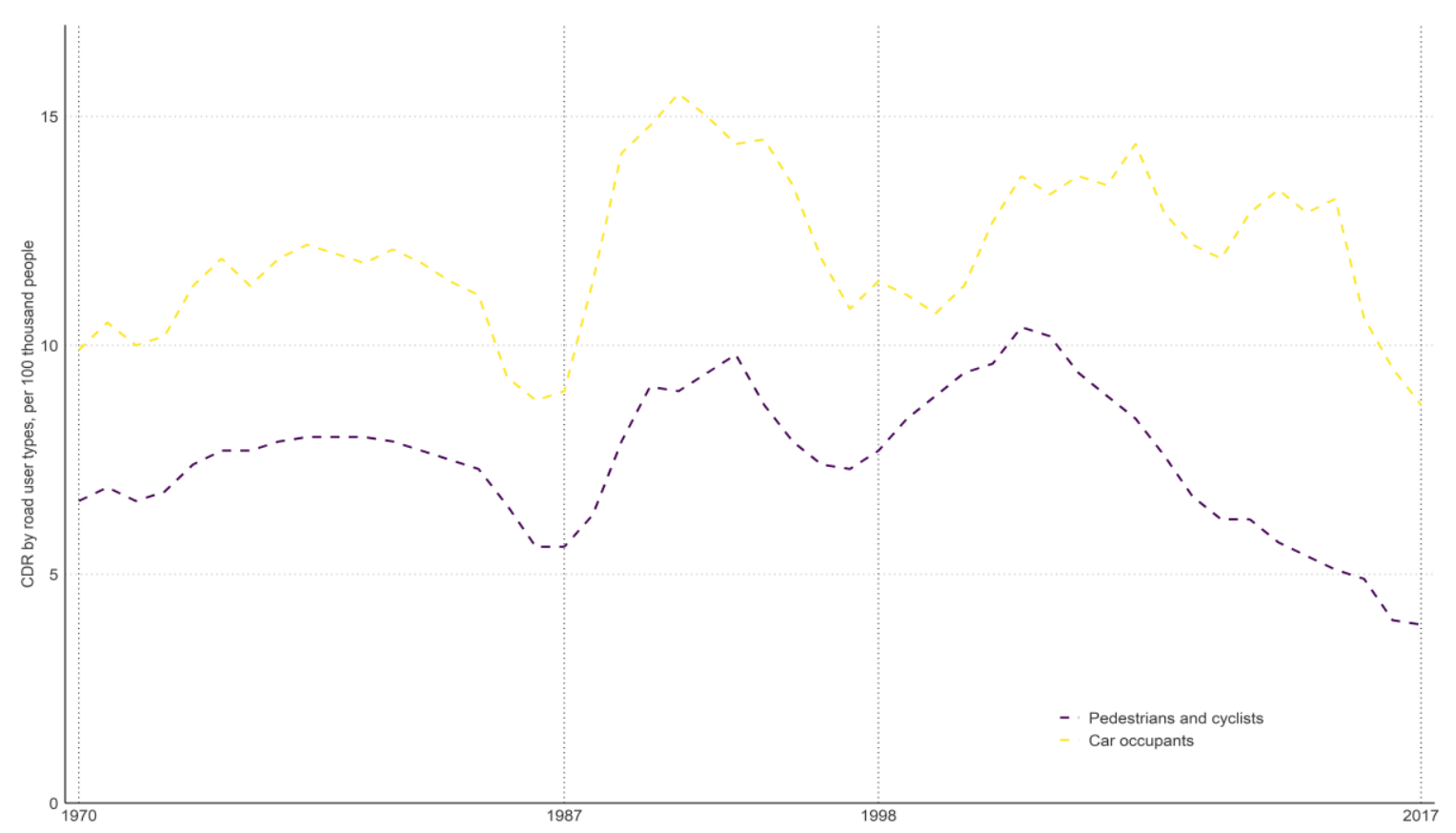

Figure 3. Mortality of the main road user types in Russia, 1970-2017

Source: Ministry of Internal Affairs data.

Comparing the crude death rates based on police data and vital statistics, we can say the following. The mortality of both road user types according to police data, while differing slightly, was consistent with similar indicators based on vital statistics until 1988. Then, an inconsistency of their dynamics begins to be observed. According to RusFMD data, the CDR of pedestrians increased from 7 to 16 deaths per 100 thousand people from 1987 to 1991 . According to police data, such a mortality increase among pedestrians and cyclists is not observed (the CDR of 
pedestrians and cyclists rose from 5.6 to 9 deaths per 100 thousand persons for the same period). Regarding the mortality of drivers and passengers, the situation is the opposite: a sharp increase according to police data (from 9 to 15.5 deaths per 100 thousand people from 1987 to 1991) and a small one according to vital statistics (from 7.8 to 9.5 deaths, respectively), which did not exceed the maximum value of the Soviet period (11.8 pedestrian fatalities per 100 thousand people in 1981). While the SC-1988 was in use, the CDR of pedestrians exceeded the CDR of drivers and passengers according to vital statistics. This phenomenon persisted until the transition to ICD-10. Since 2000, mortality of drivers and passengers has again exceeded mortality of pedestrians and cyclists according to vital statistics; its changes are now consistent with similar indicators according to police data.

Thus, in Russia, the overall level of road traffic mortality according to the two data sources is concordant, unlike mortality by road user types. The major data discrepancy occurs in the period 1988-1998.

The ratio of pedestrian mortality to car occupant mortality according to vital statistics is even more vivid evidence of the anomalousness of the period 1988-1999 (Figure 4). For both sexes, regardless of the settlement type, pedestrian mortality significantly exceeds the corresponding indicators of drivers and passengers in 1988-1999 (red shading in Figure 4, ratio greater than 1). However, before 1988 and after 1999, pedestrian mortality was generally lower or comparable to that of drivers and passengers (Figure 4, green shading, ratio less than 1). An exception is the period 1970-1988, when female pedestrian mortality in rural areas exceeded the corresponding figure for drivers and passengers by an average factor of 1.6-1.7. However, after 1988 , the ratio of the coefficients for this category also increased sharply (by a factor of up to 2.5$3)$.
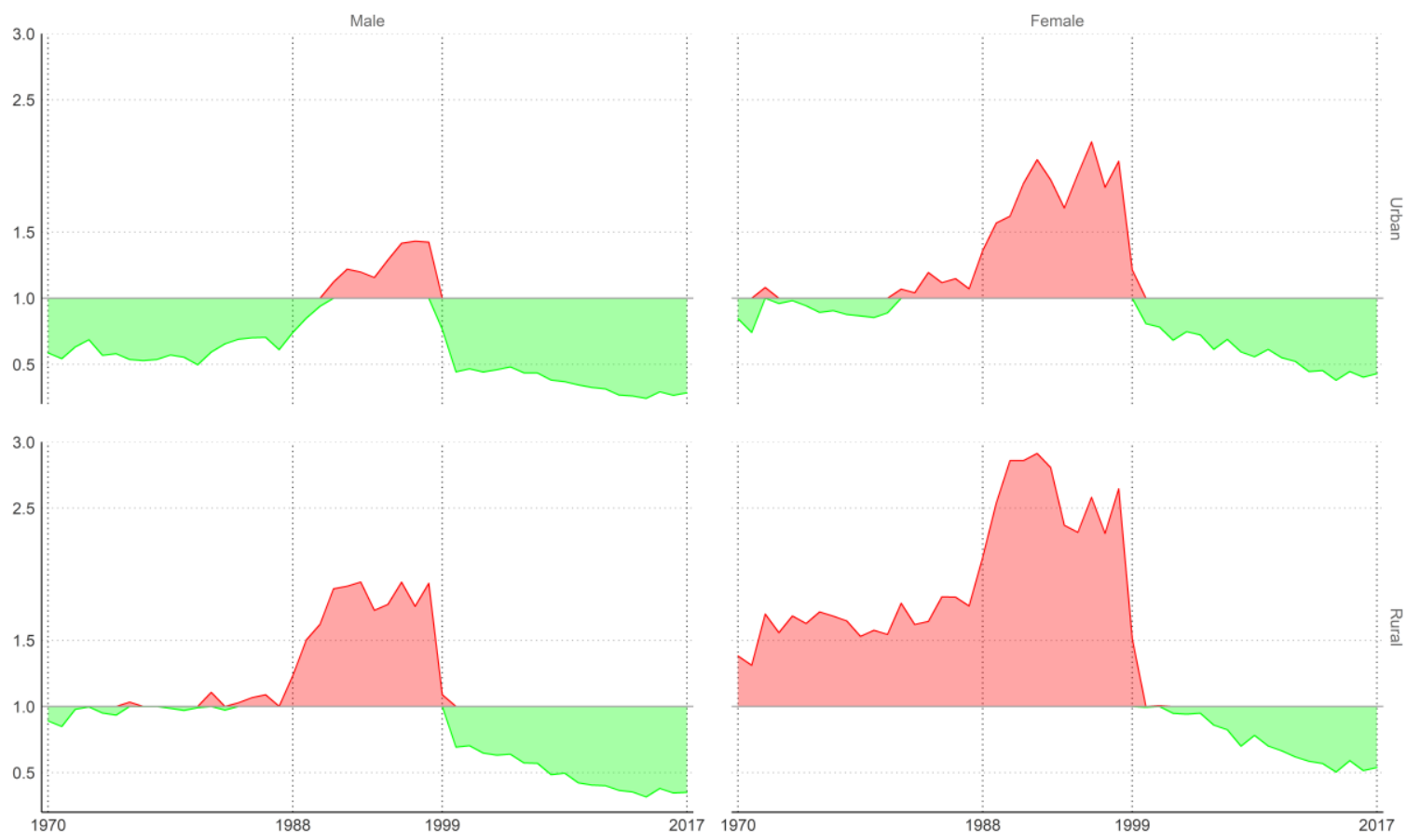

Figure 4. The sex-specific ratio of CDR of pedestrians to CDR of drivers and passengers by type of settlements in Russia in different historical periods according to vital statistics 
On the whole, such fluctuations in mortality for the main road user types are unusual, as they are not consistent with the previous and subsequent periods of observation.

Two events marked the period 1988-1999. The first is the introduction in 1988 of a new version of the Soviet abridged classification of causes of death, which abolished the division of accidents, including road traffic accidents, into work-related and non-work-related accidents (Mesle et al. 1996). The Russian item names in SC-1988, which together constitute the entire transport-related block of accidents (block E47 "Transport accidents" in ICD-9), are extremely unusual: 1) Accidents related to motor transport (160); 2) Motor vehicle accident on a public road as a result of a collision with a pedestrian (161); 3) Motor vehicle accident (162). The unusual thing is that only motor vehicles and motorised modes of transport appear in their names, and there are no other modes of transport (for example, rail, air or water). It is impossible to see a difference between item Nos. 160 and 162 in terms of the composition of accidents. The second is the transition to ICD-10 and the introduction of the corresponding Russian abridged classification of causes of death. The transition to ICD-10 came in conjunction with a change in the coding system for causes of death in the medical death certificate, as detailed in other studies (Danilova et al. 2016). It seems reasonable to assume that these two events are responsible for the peculiarity of the significant excess of pedestrian mortality over driver and passenger mortality observed during this period.

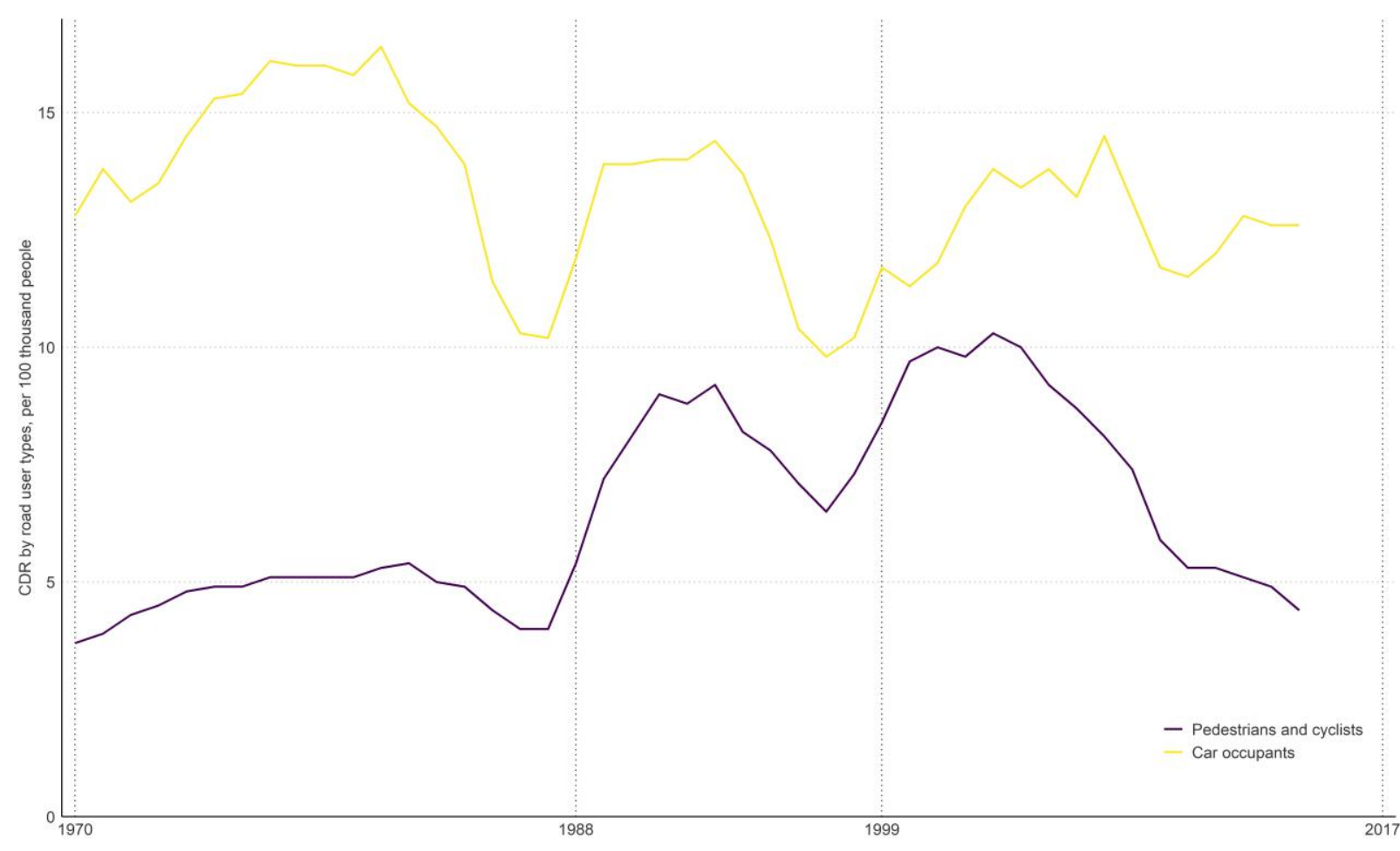

Figure 5. Mortality of the main categories of road users in Russia, 1970-2014

Source: $H C o D$ data.

To eliminate the influence of changes in abridged classifications of causes of death, we used HCoD. For Russia, it allows the construction of long time series on causes of death under the same causes of death classification - the Russian abridged classification of 2006 revision. CDR for pedestrians, just as according to police data, never exceeded the corresponding indicator for drivers 
and passengers (Figure 5). There is a second peak in pedestrian mortality in the late 1990s and early 2000s, as for drivers and passengers, although it is higher than the previous peak in the early 1990s. Mortality fluctuations by road user types are synchronous. Some questions are raised by the level of CDR of both road users before 1988, but after this year they are comparable with the police data to a greater extent than the RusFMD data.

\section{Mortality of pedestrians and drivers and passengers in some post-Soviet countries: data from state statistics of mortality and traffic police}

For international comparison, a number of post-Soviet countries (Moldova, Estonia, Latvia and Lithuania) were selected from $\mathrm{HCoD}$ with comparable headings (according to the composition of the ICD-10 cause of death codes) which can be used to identify road users. The picture of road traffic mortality by road user types in these countries is rather contradictory (Figure 6). On the one hand, in Estonia and Lithuania, the CDR of drivers and passengers is generally higher for pedestrian mortality, as in Russia according to the $\mathrm{HCoD}$ and police data. On the other hand, in Latvia, this has been true only since 1996, while before 1996 the pedestrian mortality was higher than mortality among car occupants. The turning point comes in the year of the country's transition from the last Soviet abridged classification of causes of death to ICD-10, which happened without an intermediate and short-term transition to ICD-9, as was the case in Estonia and Lithuania.

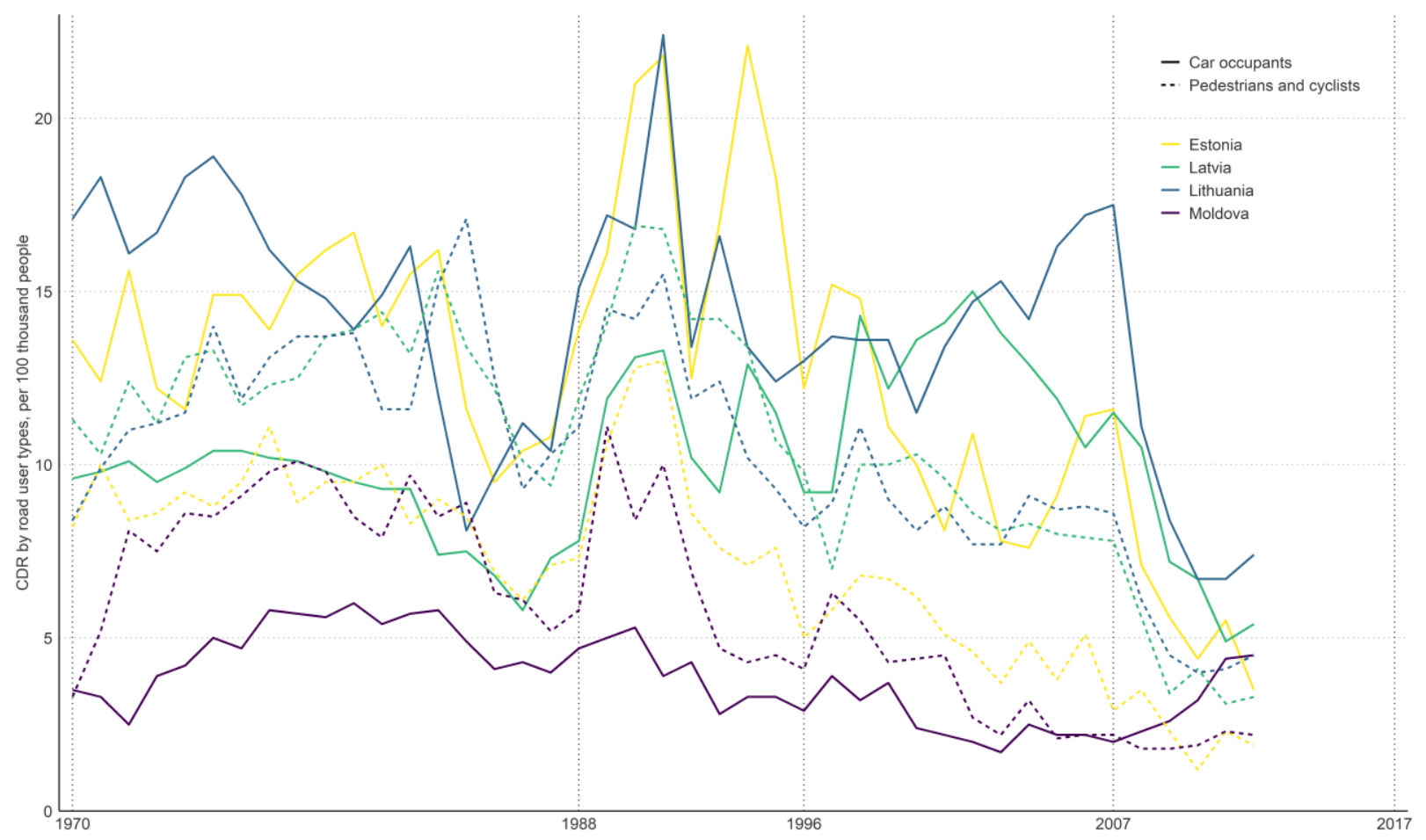

Figure 6. CDR of the main categories of road users in some post-Soviet countries, 1970-2014

Source: HCoD data.

Even more surprising is the situation in Moldova, where mortality of pedestrians up to 2006-2007 is higher than of drivers and passengers. However, the categorisation of road users under vital statistics in Moldova is difficult to trust due to the coding of the majority of road traffic 
fatalities with the V89 code "Accident involving a motorised or non-motorised vehicle of unspecified type". In 2015, in Moldova, according to the WHO Mortality DataBase, 58\% of road traffic fatalities were encoded with this code (from the set of codes V02-04, V12-14, V19, V2079, V82-87, V89). In contrast, in the Baltic countries, this code was either not used at all (Latvia, Estonia), or the number of deaths encoded by it is insignificant (Lithuania).
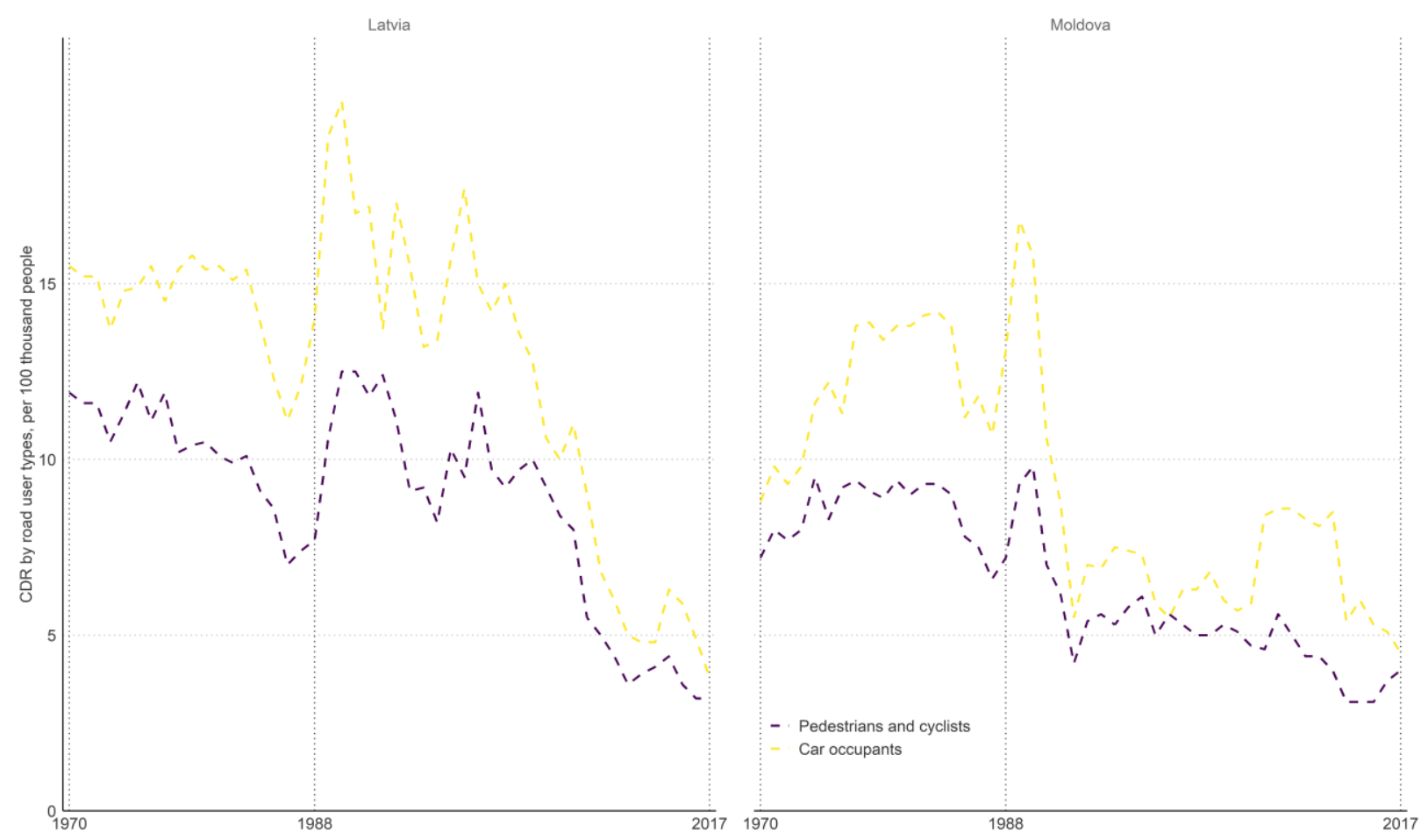

Figure 7. CDR of categories of road users in road accidents in Latvia and Moldova, 1970-2018

Source: police data of the respective countries, up to 1991 - by the soviet police data

Such different behaviour of the main road users in similar (geographically, historically, socio-economically) countries and, moreover, with abrupt reversals in some periods, raises questions. Therefore, as in Russia, we used police data for Latvia and Moldova to assess how the trends obtained on their basis correspond to those based on HcoD data (Figure 7). The results turned out to be the same as in Russia, the main one being that the mortality of pedestrians in these countries did not exceed the mortality of drivers and passengers according to police data. The sharp drop in the CDR of both road users in Moldova in 1994 is explained by the publication of data in the UNECE statistical database without data on Transnistria.

\section{Percentage of pedestrian fatalities in the total number of fatalities in road accidents: Russia compared with other countries}

In Russia, the proportion of pedestrian and cyclist fatalities in the total number of deaths in road accidents according to police data in 1993-2018 averaged 38\%. To check how their share in the total structure of deaths according to the police data corresponds to the indicators in other countries, we used international databases, where the main data source is traffic police data. 

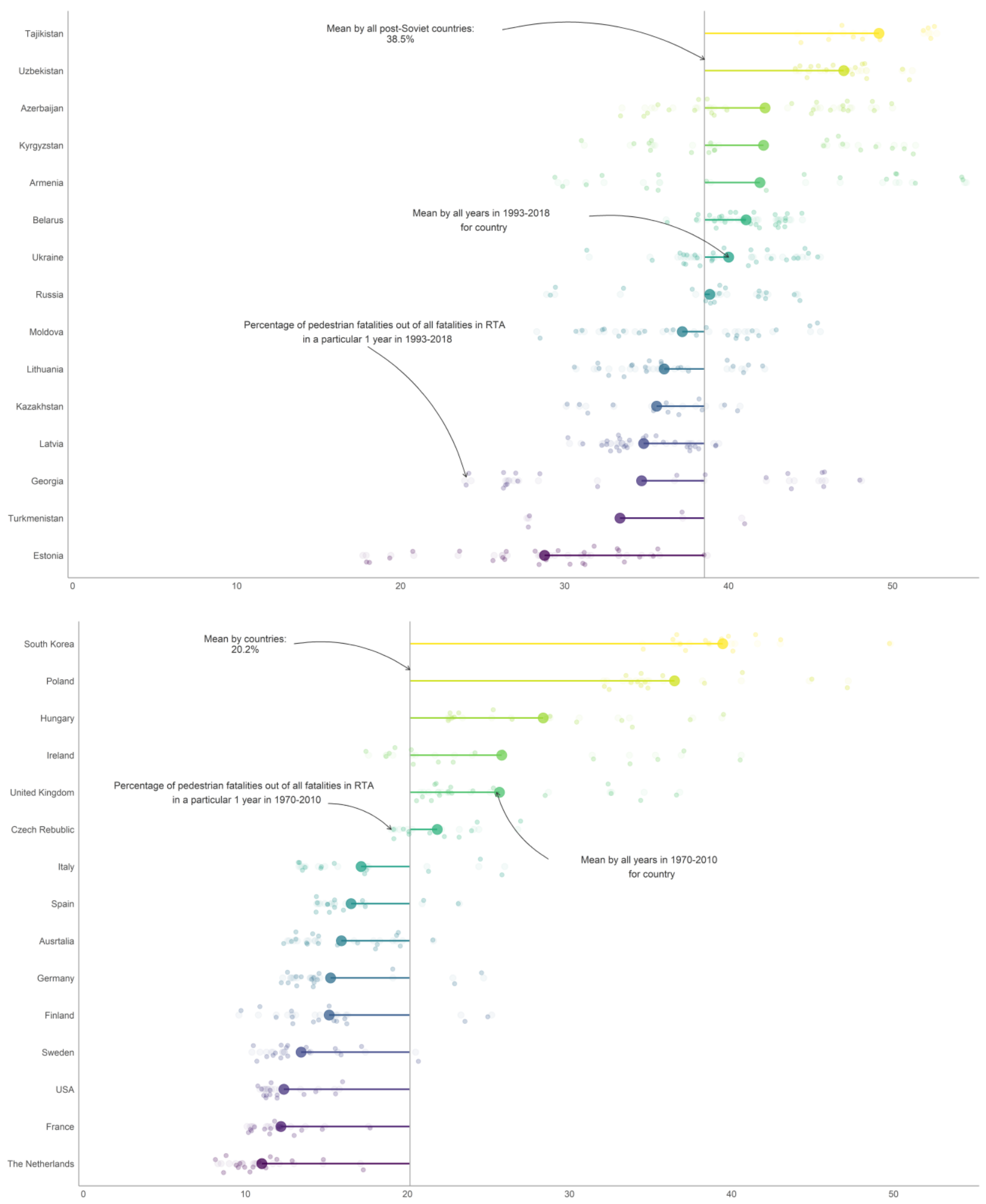

Figure 8. Percentage of pedestrian fatalities out of all fatalities in road traffic accidents in post-Soviet countries in 1993-2018 (A) and in other countries of the world in 1970-2010 (B), traffic police data, $\%$

Source: A - UNECE Statistical Database data, B - IRTAD data.

According to the UNECE statistical database, the proportion of pedestrians among all fatalities in road traffic accidents in the post-Soviet countries varies greatly both between countries and within each country in 1993-2018. Only in some years in a number of Transcaucasian 
countries (Azerbaijan, Armenia) and Central Asia (Tajikistan, Turkmenistan, Kyrgyzstan) did the share of pedestrians slightly exceed $50 \%$ of all road traffic fatalities (Figure 8a). These countries show the greatest upward deviation of the share of pedestrian fatalities from the average for all post-Soviet countries (38.5\%) in 1993-2018. Consequently, the CDR of pedestrians calculated on their basis almost never exceeded the CDR of drivers and passengers in the post-Soviet countries in 1993-2018 according to police data.

A comparison with other countries with a more or less continuous time series presented in the IRTAD statistical database shows that in them the proportion of pedestrians who died in road traffic accidents in the period 1970-2010 is significantly lower (Figure 8b) than in post-Soviet countries in 1993-2018. The closest to the post-Soviet countries is Poland, where the percentage of pedestrian fatalities in road accidents was very high in 1970 (47\%) and decreased to only 32\% by 2009. A particular exception is the Republic of Korea. In the first half of the 1990s, the proportion of pedestrian fatalities approached $50 \%$ out of total road traffic fatalities, then began to decline steadily. However, it decreased only by 1.5 times over 1990-2010, versus 3.2 times in Russia over the same period according to vital statistics (Figure 1). In other countries (Figure 8b), the percentage of pedestrian fatalities out of total road traffic fatalities also decreased in 1990-2010, but the decline did not exceed 1.5 times in any country.

Neither in the post-Soviet countries nor in the European countries, the United States and South Korea did the share of pedestrians consistently exceed $50 \%$ of the total number of deaths in road traffic accidents by police data, with the exception of some years in some countries, when this figure was only approaching this mark. Therefore, it could be concluded that the Russian figures based on police data are in line with similar indicators in other countries.

\section{Discussion}

The anomalous excess of pedestrian mortality over car occupant mortality according to RusFMD in Russia in 1988-1999 was shown using different data sources, including those based on different reporting systems. Possibly this is due to the peculiarities of the cause of death classifications used, under which the data are presented. We believe that there was no excess of pedestrian mortality over car occupant mortality for 10 years from 1988 to 1999. This is confirmed by the police data of Russia and other countries and by Russian vital statistics presented under a unified cause of death classification in $\mathrm{HCoD}$.

Given that, pedestrian mortality has most likely been steadily decreasing not since 1991-1993, but since 2003, having already dropped significantly below the minimum values of the Soviet period. After ups and downs, the mortality of drivers and passengers decreased to the level of the early 1970s only in 2015-2017.

Unfortunately, we did not find a direct cause of such unusual behaviour of mortality among pedestrians and drivers and passengers according to RusFMD data in 1988-1999. One of the possible, but highly speculative, explanations is the assumption that in the RusFMD data in 1988-1999 the names of item Nos. 160 and 161 were switched ("Accidents related to motor vehicles" and "Motor transport accident on a public road as a result of a pedestrian collision") . Under this assumption, if item 160 is assigned the values of item 161 and vice versa, the CDR for 
pedestrians and the CDR for drivers and passengers (pale blue and pale orange lines in Figure 9, respectively) in 1988-1998 will correspond to coefficients according to the police (Figure 4) and HcoD data (Figure 6).

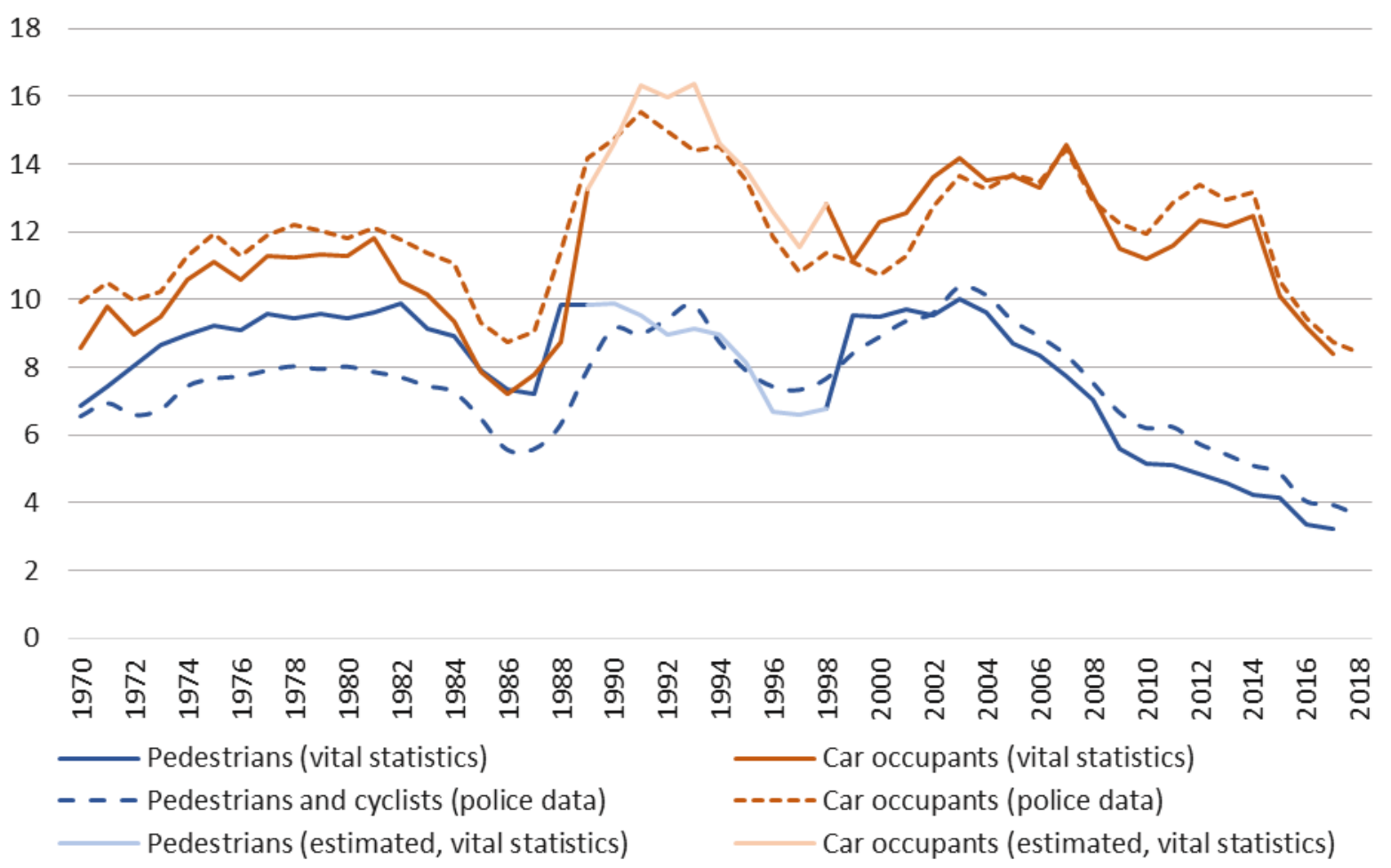

Figure 9. Estimated and actual CDR of road users according to vital statistics (solid lines) in Russia

As a result of such a rearrangement, all the questions posed at the beginning of the study disappear. Pedestrian mortality almost never exceeds mortality of drivers and passengers, having become equal only during the anti-alcohol campaign in 1985. This behaviour generally agrees with world indicators. Changes in the coefficients are synchronous, and the increase in the mortality of drivers and passengers after the abolition of the anti-alcohol campaign in 1985 was sharp and significantly higher than in the late 1990s and early 2000s.

A riskier form of driver behaviour in the USSR in the late 1980s and early 1990s was noted in the statistical bullitens published by the Ministry of Internal Affairs. In line with them, in the USSR in 1989, 49.1 thousand people died due to the fault of drivers, including 11.6 thousand people due to the fault of drunk drivers of vehicles, while 10.8 thousand deaths were due to the fault of pedestrians, including 2.04 thousand through the fault of drunk pedestrians. In 1989 in the USSR, a fifth of road traffic fatalities were due to the fault of drunk road users, but 5 times more to the fault of drunk drivers than to drunk pedestrians (Scientific Research Center for Road Traffic Safety... 1990). In addition to drunk driving, the police noted that "in 1989, persons who do not have the right to drive motor vehicles committed $71.8 \%$ of all road traffic accidents in which $72.8 \%$ of the corresponding indicators of accidents in individual transport died" (Scientific Research Center for Road Traffic Safety...1990).

The example of Moldova shows that it makes sense to analyse mortality by aggregated categories of road users according to mortality statistics only if there is a small proportion of deaths 
coded by an unspecified V-code (V89). Otherwise, the structure of fatalities by road user types will be distorted if this code is not included in any of the specified categories of road users. It is worth noting that a high proportion of road traffic deaths encoded with V89 is typical not only for Moldova, but also for countries such as the United States (according to the WHO Mortality Data Base, the proportion of deaths in road traffic accidents encoded with V89 in 2014 was 32.4\%), Portugal (57\% in 2014), Romania (69\% in 2015) and France (72\% in 2014). The number of deaths in road traffic accidents, defined as the sum of the deaths only under the specified items in terms of road user types, may be underestimated (in the case of Moldova, Nos. 195 and 196) due to the following reasons: 1) Data source does not allow for grouping three-digit codes of causes of death; 2) The V89 code is attributed to the aggregated group of other transport codes; 3) The proportion of deaths encoded by it is significant.

In Russia, the problem of using unspecified transport causes of death codes ( $\mathrm{V}$-codes), including V89, also occurs (Semenova et al. 2013). Nevertheless, it is not as pronounced as in the countries listed above. In 2000, the share of deaths coded with the V89 code in the total number of deaths in road traffic accidents (codes V02-04, V12-14, V19, V20-79, V82-87, V89) came to $8.1 \%$, and by 2016 had dropped to $4.4 \%$. A study of the US found that the characteristics of unspecified categories of traffic accident fatalities are similar to those of protected road users (drivers and passengers) (Mack et al. 2019). Therefore, in the case of Russia, given the small number of deaths coded by V89, we attributed these deaths to drivers and passengers.

\section{CONCLUSION}

In the police reporting system the classification of road users has not changed. Its distinguishing feature is the absence of an unspecified category of road users, that is, the deceased is always assigned to one of the clearly defined categories. In vital statistics, there is no classification of road users as such. It depends on the approach to the aggregation of the codes of the International Classification of Diseases (ICD), its version and, which is essential in the case of Russia, the version of the abridged classification of causes of death in force within a particular revision of the ICD, as well as its Russian translation.

In the case of Russia, it is more reasonable to rely on police data concerning the mortality of road users. Of course, this statement is not true for all countries. For example, in China and India, there is an underestimation of injured pedestrians, including fatalities, according to published police reports (Bhalla et al. 2017; Hu, Ma, Zhou 2012; Li et al. 2016; Singh et al. 2018). The problem of determining the category of road user in the vital statistics exists not only in Russia, but also in the United States, where protected road users are a problem group (Mack et al. 2019). In Russia, the situation is different. Pedestrians are mainly coded as being in an unspecified road or non-road traffic accident. As a result, they do not even fall into the total number of road traffic deaths if the abridged classification is applied for data analysis (Pyankova et al. 2019). This problem vanishes if detailed cause-of-death ICD-10 codes are used and grouped according to one of the international approaches for defining the number of deaths in road traffic accidents, as was done in this study. 
The use of vital statistics is appropriate if it is necessary to make a differential analysis of road traffic mortality by sex, age and type of area in Russia. When it is necessary to analyse mortality by road users types, Russian vital statistics have some limitations and should be used with caution. In our opinion, it is reasonable to use the following open data sources: 1) HCoD data since 1988; 2) RusFMD data from 1970 to 1988 and after 1999, excluding 1989-1998.

Comparisons of Russia with Latvia and Moldova have shown that similar difficulties in analysing long-term mortality trends by road users based on mortality statistics can arise in postSoviet countries where the Soviet abridged classification of causes of death was used. However, this issue requires further study.

\section{REFERENCES}

Bhalla K., Khurana N., Bose D., Navaratne K.V., Tiwari G., Mohan D. (2017). Official government statistics of road traffic deaths in India under-represent pedestrians and motorised two-wheeler riders. Injury Prevention, 23(1), 1-7. https://doi.org/10.1136/injuryprev-2016-042053

Charters K.E., Gabbe B.J., Mitra B. (2017). Population incidence of pedestrian traffic injury in high-income countries: A systematic review. Injury, 48(7), 1331-1338. https://doi.org/10.1016/j.injury.2017.05.021

Danilova I., Shkolnikov V.M., Jdanov D.A., Meslé F., Vallin J. (2016). Identifying potential differences in cause-of-death coding practices across Russian regions. Population Health Metrics, 14(1). https://doi.org/10.1186/s12963-016-0078-0

Eid H.O., Abu-Zidan F.M. (2015). Pedestrian injuries-related deaths: A global evaluation. World Journal of Surgery, 39(3), 776-781. https://doi.org/10.1007/s00268-014-2853-z

Hu G., Ma S., Zhou M. (2012). Hidden increasing pedestrian fatality between 2006 and 2010 in China: findings from non-police-reported data. Injury Prevention, 18 (Suppl 1), A220.3A221. https://doi.org/10.1136/injuryprev-2012-040590v.7

Li Q., He H., Liang H., Bishai D.M., Hyder, A.A. (2016). One outcome, many trends: Understanding national data sources for road traffic fatalities in China. American Journal of Public Health, 106(10), 1793-1795. https://doi.org/10.2105/AJPH.2016.303287

Mack K.A., Hedegaard H., Ballesteros M.F., Warner M., Eames J., Sauber-Schatz E. (2019). The need to improve information on road user type in National Vital Statistics System mortality data. Traffic Injury Prevention, 20(3), 276-281. https://doi.org/10.1080/15389588.2019.1576036

Mesle F., Shkolnikov V., Hertrich V., Vallin J. (1996). Recent trends in mortality by causes of death in Russia during 1965-1994 [In French and Russian]. http://www.demoscope.ru/weekly/knigi/shkol/shkol.html

Naci H., Chisholm D., Baker, T.D. (2009). Distribution of road traffic deaths by road user group: A global comparison. In Injury Prevention (Vol. 15, Issue 1, pp. 55-59). BMJ Publishing Group Ltd. https://doi.org/10.1136/ip.2008.018721

NITS po BDD MVD SSSR. Dorozhno-transportnyye proisshestviya v SSSR (Statisticheskiy sbornik za 1970-1989). (in Russ).

NITS po BDD MVD SSSR (1990). Dorozhno-transportnyye proisshestviya v SSSR (1985-1989 gg.). (in Russ). 
Prestupnost' i pravonarusheniya v SSSR. Statisticheskiy sbornik.1989 (1990). (in Russ).

Pyankova A.I., Fattakhov T.A. (2020). Road traffic mortality in Russia: definitions, trends and perspectives. Demographic Review, 6(5), 120-140. https://doi.org/10.17323/demreview.v6i5.11463

Pyankova A.I., Fattakhov T.A., Bakanov K.S., Yurasova E.D. (2019). Road traffic mortality in Moscow: record linkage study using police data and vital statistics. Demographic Review, 6(1), 151-176. https://doi.org/10.17323/demreview.v6i1.9115

Semenova V.G, Antonova O.I., Nikitina S.Yu., Borovkov V.N., Yevdokushkina G.N. (2013). The issues of reliability of mortality statistics due to traffic accidents. Zdravookhranenie Rossiiskoi Federatsii [Health care of the Russian Federation], 4, 33-37 (in Russ). Retrieved from http://www.demoscope.ru/weekly/2014/0593/analit01.php

Sengoelge M., Laflamme L., El-Khatib Z. (2018). Ecological study of road traffic injuries in the eastern Mediterranean region: Country economic level, road user category and gender perspectives. BMC Public Health, 18(1). https://doi.org/10.1186/s12889-018-5150-1

Singh P., Lakshmi P.V. M., Prinja S., Khanduja P. (2018). Under-reporting of road traffic accidents in traffic police records- a cross sectional study from North India. International Journal Of Community Medicine And Public Health, 5(2), 579. https://doi.org/10.18203/2394-6040.ijcmph20180232

UNECE Statistical Database (2020). Persons Killed or Injured in Road Traffic Accidents by Category of User. https://w3.unece.org/PXWeb2015/pxweb/en/STAT/STAT_40TRTRANS_01-TRACCIDENTS/09_en_TRAccKTGory_r.px/

Vishnevsky A.G. (Ed.) (2017). Mortality from external causes in Russia since the mid-20th century. Moscow: HSE Publishing House (in Russ.) https://doi.org/10.17323/978-5-75981397-2

World Health Organization. (2018). Global status report on road safety 2018.

Yasin Y.J., Grivna M., Abu-Zidan F.M. (2020). Reduction of pedestrian death rates: a missed global target. World Journal of Emergency Surgery, 15, 35. https://doi.org/10.1186/s13017020-00315-2 